at sea which has been attained during the last ten years is demonstrated, and the altogether exceptional character of the circumstances which attended the loss of the Titanic is made clear.

The main recommendations of the report may be summarised. First, it is recognised that "the stability and seaworthy qualities of the vessel itself " must be regarded as of primary importance. This includes the question of watertight subdivision, now under investigation by a special committee. Second, as regards boats and life-saving appliances it is recommended that accommodation should be provided for the total number of persons which each foreign-going passenger steamship is licensed to carry. This has not been done hitherto in the largest passenger steamships, but the report shows that the rules hitherto in existence for such ships were sufficient to provide boats carried under davits for all persons in 343 out of 52 I such ships which were examined, and that out of the 178 ships for which these rules did not require sufficient boats under davits for all persons carried no fewer than forty-nine ships actually carried sufficient boats, their equipment going beyond legal requirements.

For passenger steamers in the home trade--plying in estuaries and rivers, cross-channel and coasting services, etc. - the recommendation made is that the boats, life-rafts and buoyant apparatus taken together should aggregate accommodation for not less than 50 per cent. of the passengers and crew. The conditions under which these vessels work obviously render it probable that, in most cases, external help would soon be available in case of accident, and the sub-committee says that there is "a consensus of opinion that in these smaller vessels any considerable increase in the number of boats is not practicable and would be a source of danger rather than an element of safety." While the force of this argument is undoubted, it is proper to add that the considerations urged therein make it imperative that the officials of the Board of Trade in granting passenser certificates and fixing the maximum numbers to be carried should also have regard thereto.

One must be impressed afresh in reading this report with the fact that even when the provision of boats and life-saving appliances is ample, there are comparatively few cases in which these can be fully utilised in case of serious accident. In the case of the Titanic the boat accommodation which existed was not fully utilised, although the boats were safely lowered and a calm prevailed. Modern ocean-going steamers carry their boats at great heights above water, and with any rolling motion of the vessel it is dangerous, if not impossible, to lower the boats. In very moderate weather it may be done, but even then occupies much time. This matter has been referred to another departmental committee, the labours of which are just beginning.

When the reports have been presented from the Committee on Boat Lowering Appliances and from the Bulkhead Committee, the President of the Board of Trade and his staff in the Marine Depart- ment will have much further material for consideration, in addition to the great mass of facts and opinions contained in the report now before us. One is disposed to ask: What will he do with it? Captain Hampson, a member of the Advisory Committee, in a lengthy reservation, which is severely dealt with by the chairman in a separate note, strongly urges the appointment of "a commission or committee composed of members independent in every way of the shipping interest, but at which various representatives of the different sections of shipping should be invited to submit their views." Such a course appears to be most undesirable; it would amount to an abandonment of the investigations by competent committees already set on foot. The materials on which future regulations ought to be based will be ample when existing committees have finished their labours, and the responsibility for these regulations must be accepted by the President of the Board of Trade. This general statement of the case applies not only to the points mentioned above, but to other important matters, including manning of British ships, boat drills, wireless telegraphy, the use of searchlights, rules. for navigation, and others which cannot be mentioned.

In one direction the Advisory Committee appears to have undertaken a gratuitous task, as it has investigated the advance made in the speed of ocean-going steamships in order to demonstrate that the general increase has been small and that even now ships exceeding twenty knots are few in number. The really important question is not what maximum sea speed a ship can maintain, but what is an "undue speed" likely to lead to accidents in special circumstances. The committee itself recognises this distinction and one of its most valuable recommendations is that proposing to extend the present regulations and to. prescribe to those in charge of ships the necessity for proceeding at moderate speed "at night in the known vicinity of ice." Anything less than this, after the loss of the 'Titanic, would be contrary to public feeling and to common sense.

\section{FORESTS AND RAINFALL}

GIR W. SCHLICH, F.R.S., Professor of $\checkmark$ Forestry at Oxford, writing in the new edition of the "Encyclopadia Britannica," defines a forest as "an area which is for the most part set aside for the production of timber and other forest produce, or which is expected to exercise certain climatic effects, or to protect the locality against injurious influences." One of the most important of the climatic effects ascribed by some to forests is the increased amount of precipitation, not only in the forest areas themselves, but also in the country surrounding them, produced by the influence of the forests upon the moisture-laden air which passes over them.

Owing to the relatively small area of our forests and the rarity of serious floods or prolonged 
droughts, the question of the influence of forests upon rainfall has not received much attention in this country, but on the Continent,--in France, Germany, and Austria especially,-in America, and, more recently, in India, the arguments for and against the existence of any influence have been put forward at great length, and sometimes with much energy.

The literature on the subject is somewhat bewildering, not only on account of its extent, but also because of the surprising divergence of views entertained by different authorities. Most European and some American writers are in favour of the accuracy of the supposed forest influence, while other American authorities maintain that the effect is entirely fictitious; that the instrumental records which have been adduced in support of it are affected by errors brought about by differences of exposure in the forest and in the open, and that, if there is a connection between forests and climate, it is the latter which controls the growth of the former, the former having no appreciable effect on the climate.

On one side the problem has been attacked by the historical method; that is, the state of a forest and the amount of rainfall in its vicinity are compared together over as long a period as possible. On account of the lack of trustworthy records of rainfall for the long periods required, the fall is usually estimated from accounts of the condition of some stream or river in the neighbourhood. As an example of this method may be cited the case of the river Loire, which in former times afforded communication by water between Nantes and the central provinces of France. In $\mathrm{I}_{55} \mathrm{I}$ the Marquis of Northampton went from Orleans to Nantes, with his suite, in "five large, many-cabined boats," whereas navigation is now impossible above Saumur, the distance of which from Nantes is less than half that of Orleans. This change is ascribed to the deforestation carried on extensively in the surrounding country in the seventeenth century, and the consequent diminution in the volume of water in the Loire due to diminished rainfall. It is here tacitly assumed that the general climate over Western Europe has remained unaltered throughout the period, and that any change in the climatic conditions is due to local forest influence, secular changes of climate being entirely overlooked.

The strongest arguments in favour of the supposed influence are based upon observations at so-called "parallel" stations; i.e. meteorological stations are established within a forest area and in the open country round the forest, respectively, and a long series of simultaneous observations are made at all the stations. In nearly all localities where such observations have been carried out, an appreciable difference exists between the rainfall measured inside the forest and that measured outside, the forest station having an excess of precipitation over the "parallel" station. A remarkable example is that of Lintzel, in Hanover. In I 882 the rainfall at this station was considerably less than at most neighbouring stations. Young trees were planted round the station in 1877 , and as they grew up the rainfall at Lintzel gradually increased in comparison with its neighbours, unti] in 1890 it was generally in excess where in 1882 it had been in defect. The objection urged against the historical method does not apply to this kind of reasoning, which appears conclusive on the face of it. In a series of recent papers in the Meteorologische Zeitschrift, J. Schubert has shown that a forest station in West Prussia and Posen has from 2 to Io per cent., and in Silesia from 2 to 6 per cent. more rainfall than a parallel station in the open country. From this it is argued that inasmuch as a forest increases the rainfall over its own area, it may be expected to produce some effect of the same kind in the surrounding districts, because the wind would carry forward the rainbearing clouds formed by the forest influence.

The value of observations derived from parallel stations has, however, been strongly criticised by some American meteorologists. Prof. Cleveland Abbe has urged that the results are vitiated on account of the fact that a rain gauge exposed in a forest clearing is not subjected to winds as strong as those which pass over a gauge at a parallel station in the open country; and that, in consequence, the forest gauge may be expected to record more rain, although the real fall may be identical at the two places. As a result of his investigations, Abbe is of opinion that there is no appreciable difference in the rainfall outside and inside a forest. Schubert was aware of the force of this contention, and definite allowance was made for difference of exposure in the results quoted above. His margin is, however, so small, and the correction allowed on account of exposure differences is so uncertain, that his final result cannot be regarded as furnishing a conclusive solution of the problem.

In a report on the "Influence of Forests on Climate and on Floods," Prof. Willis L. Moore, Chief of the United States Weather Bureau, brings forward some considerations against the supposed effect of forests on rainfall. One piece of evidence shows how climate affects the extent of a forest area, and suggests that the influence, if any, is from climate to forest, and not conversely. $\mathrm{Mr}$. E. Huntington, travelling in Chinese Turkestan, stated that "poplar forests, which once extended for scores of miles, now form wastes of branchless dead trunks, like gaunt grey skeletons, and beds of dead reeds cover hundreds of square miles. It has often been asserted that the destruction of forests has been the cause of the diminution of rainfall. In the Lop basin the opposite appears to be the case; the supply of water has diminished, and therefore the forests have died."

The physical explanation for the increased rainfall which is put forward is that the evidence is undisputed that air temperature is less and percentage humidity is greater over a forest than over the neighbourhood. In favourable circumstances, condensation of water vapour may therefore be set up over a forest, and once the condensation has started, it may continue automatically, owing to the large amount of latent heat

$$
\text { NO. } 2235 \text {, VOL. 89] }
$$


liberated in the process of condensation, which will tend to set up convection currents.

Prof. J. von Hann's opinion on the subject, in the latest edition of his "Handbuch der Klimatologie" is that the question cannot be definitely answered at present, but that the effect, if any, should be greater in the tropics than in higher latitudes. Dr. G. T. Walker, of the Meteorological Office, Simla, is of a similar opinion. He states that if forests have any influence at all on the rainfall, it is probably not greater in India than 5 per cent.

R. C.

\section{OERSTED AND THE ELECTRIC THEORY} OF LIGHT.

I N Sir John W. F. Herschel's classical article on light (dated 1827 ) in the "Encyclopædia Metropolitana" of 1830 , p. 439, there is a vague reference to a theory of light then recently propounded by Oersted, in which he sought to explain the nature of light-waves as a succession of minute electric sparks. Desiring to follow up this reference, the writer of this notice consulted, but fruitlessly, all the writings of Oersted within his reach. Thereupon he applied for information to Prof. Absalon Larsen, of Copenhagen, who, after consultation with Prof. Christiansen, kindly directed the writer to sources not available in London, and furnished the extracts now given from Oersted's writings.

The theory of light suggested by Oersted was first advanced in a remarkable book, written in the German language, and published in Berlin in 1812 , under the title, "Ansicht der chemischen Naturgesetze," von H. C. Oersted. The theory of light occupies only a small part of this book (298 pages in all), which is of a much wider scope. Oersted proposes to refer all chemical phenomena to fundamental agents (forces), hoping thus to initiate a development of theoretical chemistry analogous to the development which the introduction of simple laws had brought about in mechanics. A quotation from his own introduction, pages $7-9$, will state the position:-

It will not be without use here at the outset to review the whole road to be travelled. We intend to make the beginning of our investigation with a demonstration and arrangement of all bodies according to their chemical nature. Then we will set forth some considerations about the ordinary chemical actions known to us, and will show from them that all chemical changes hitherto investigated can be referred to two widely extended forces of Nature. We will at the same time demonstrate that these forces are able to act not only by direct, but also by indirect, contact; that consequently they can be conducted. This will lead us to those chemical circuitactions which have already been known to us for a long time in Galvanism. And, lastly, this will bring us on to demonstrate chemical forces in their free activity, and so at the same time to make evident their identity with electrical forces. Here, then, we shall reverse the course of our investigation, and directing our attention to electrical forces, we shall seek to discover how these also can be related to the chemical form of action. And besides we then become aware that the electric forces, like the chemical ones, are two, and that they at the same time are opposed; that both are of general application, and that, from the state of relative rest in which they exist in bodies, they can pass over into activity when aroused by external forces. ... After we have in this way set forth the broad connection of chemical and electrical actions, in these two opposite directions, we shall, relying on an investigation into the nature of conduction, try to show under what conditions the two forces produce Heat, and under what conditions they produce Light. We shall thereby regard these great phenomena in a far more intimate connection with the rest of nature than werc possible according to the ordinary view.

Starting from the nature of electric conduction, Oersted then attempts to show the conditions under which the two opposing agencies produce heat and light respectively. His ideas about conduction he develops on pages 138 , I 39 :-

If, therefore, one of the electric forces is propagated through space, this occurs in the following way: that it attracts the opposing force in the nearest zone, binds it, and itself in turn suffers a diminution from it, in consequence of which the next zone receives actually the overplus of the same force as it spreads, but itself excites a new zone of the opposing force, so as again to react, and so forth. One may express all this by saying that Electricity is propagated by wave-motion (die Electricität verbreitet sich undulatorisch).

As to the conditions under which the conduction of electricity produces heat, Oersted writes on pp. $164-165:-$

We have seen that Conduction consists in a disturbance running through all points of the body and in a restitution of equilibrium. So long as the Conduction is complete, the restitution will always be brought about by the mutual attraction of the force evoked out of equilibrium. But when by reason of a forced conduction a greater quantity of force penetrates the body than the latter is able spontaneously to conduct away, then at once the interiorly-disturbed equilibrium cannot be restored again by the body's own forces... This condition, in which equilibrium is disturbed at every point of the body, but in such wise that no recognisable separation of the forces is attained, gives us the phenomenon of Heat. ...

To distinguish it from other theories of heat, the mechanical, which regards heat as a vibration of material particles, and the chemical, which assumes a particular substance (caloric), Oersted calls his own the dynamical theory.

As regards light, Oersted first shows that heat may be transformed into light, and vice versâ, and he therefore considers heat and light as produced by the same two agencies. The difference is that, as stated above, for the production of heat no real separation of the two agencies is needed, whereas for the production of light the tension of the opposite forces or agencies must reach its maximum value and produce a discharge. The following passages are from p. 222 :-

so we must content ourselves with knowing that Light will be produced if the tension of opposition of the internal forces has attained its maximum and passes over into equalisation. 